\title{
COMPARATIVE ANALYSIS OF METHODS FOR ASSESSING THE TRANSITION TO A GREEN ECONOMY ${ }^{1}$
}

\author{
Marina A. Lebedeva \\ Vologda Research Center of the Russian Academy of Sciences, Vologda, Russian Federation
}

\begin{abstract}
The concept of sustainable development has become the basis for the future of humanity, and one of the tools for achieving it is green economy, which needs to be evaluated by offering certain methods of measurement. The purpose of this work is a comparative analysis of the most well-known methods for evaluating the implementation of the green economy concept at the national and regional levels, identifying their advantages and disadvantages. The analysis of foreign and domestic literature has shown that two types of integral indices are used mainly to measure the "greening" of economy: indices whose constituent elements require normalization (The Global Green Economy Index, The Index of the Green Economy, The Green Growth Index, The Ecological Footprint) and the indices that comprise the indicators which have a common unit of measurement (The Index of Adjusted Net Savings, "Green GDP"). As a result of the research, it was found that the normalized indices do not fully meet the criteria for aggregate indicators presented by the OECD. In addition, all the considered methods allow only to reflect trends towards the transition to a green economy, but not to assess the degree of its implementation. Further research will develop a set of indicators that can be used to characterize not only trends, but also the specific stage of transition to a green economy.

Key words: green economy, sustainable development, global green economy index, green growth index, adjusted net savings index, "green GDP".

Citation. Lebedeva M.A. Comparative Analysis of Methods for Assessing the Transition to a Green Economy. Journal of Volgograd State University. Economics, 2020, vol. 22, no. 3, pp. 109-122. (in Russian). DOI: https:// doi.org/10.15688/ek.jvolsu.2020.3.10
\end{abstract}

УДК 303.101

Дата поступления статьи: 20.05.2020

ББК 65.05

Дата принятия статьи: 02.07.2020

\section{СРАВНИТЕЛЬНЫЙ АНАЛИЗ МЕТОДИК ОЦЕНКИ ПЕРЕХОДА К ЗЕЛЕНОЙ ЭКОНОМИКЕ ${ }^{1}$}

\author{
Марина Анатольевна Лебедева \\ Вологодский научный центр РАН, г. Вологда, Российская Федерация
}

\begin{abstract}
Аннотация. Устойчивое развитие стало основой для будущего человечества и одним из инструментов его достижения является зеленая экономика, для оценки реализации которой необходимо предложить определенные способы измерения. Целью данной работы является сравнительный анализ наиболее известных методик оценки реализации концепции зеленой экономики, выявление их достоинств и недостатков. Анализ зарубежной и отечественной литературы показал, что главным образом для измерения «озеленения» экономики используются интегральные индексы двух типов: индексы, составные элементы которых требуют нор§ิ мализации (Глобальный индекс зеленой экономики, Индекс зеленой экономики, Индекс зеленого роста, ○ิ Экологический след), и индексы, составляющие показатели которых имеют общие единицы измерения (Ин¿ декс скорректированных чистых накоплений, «Зеленый ВВП»). В результате было выявлено, что нормализуемые индексы не в полной мере соответствуют критериям агрегированных показателей, предъявляемых ОЭСР. Кроме того, все рассмотренные методики позволяют только отражать тенденции в сторону перехода к зеленой экономике, но не оценивать степень его реализации. В дальнейших исследованиях будет разработан набор показателей, с помощью которого можно охарактеризовать не только тенденции, но и конкретный этап перехода к зеленой экономике.
\end{abstract}


Ключевые слова: зеленая экономика, устойчивое развитие, глобальный индекс зеленой экономики, индекс зеленого роста, индекс скорректированных чистых накоплений, «зеленый ВВП».

Цитирование. Лебедева М. А. Сравнительный анализ методик оценки перехода к зеленой экономике // Вестник Волгоградского государственного университета. Экономика. - 2020. - Т. 22, № 3. - С. 109-122. DOI: https://doi.org/10.15688/ek.jvolsu.2020.3.10

\section{Введение}

Разнообразные кризисы последнего времени показывают неустойчивость сложившейся модели экономического развития как в мире, так и в России. Важный недостаток этой модели - абсолютизация экономического роста в ущерб решению социальных и экологических проблем [Зеленая экономика ..., 2019; Проблемы экономического роста ..., 2013]. В то же время практика доказывает, что устойчивый рост экономики является единственным источником увеличения доходов и, соответственно, инвестиций для борьбы с бедностью, повышения уровня доступности услуг образования и здравоохранения, ликвидации накопленного экологического ущерба, «зеленой» модернизации производства, способствующей снижению ресурсоемкости экономики и нагрузки на жизнеобеспечивающие экосистемы окружающей среды [Порфирьев, 2020; Ускова, 2009].

При этом взаимосвязь природы и экономики выражается не только в прямом воздействии, но и обратном. Ущерб экологии может в значительной степени отразиться на экономической ситуации в мире. По данным Восточного экономического форума, от устойчивости экосистем зависит до половины мирового ВВП (44 трлн долл. США). При этом $52 \%$ мирового ВВП приходится на отрасли, зависимые от состояния экосистем [Лабыкин и др., 2020, с. 60].

Одним из перспективных путей минимизации данных угроз является обеспечение устойчивого развития. Под устойчивым развитием понимается достижение желательного равновесия между экономическим ростом, справедливым развитием человеческого потенциала и здоровыми экосистемами [Ускова, 2009, с. 25].

Концепция устойчивого развития стала основной для будущего человечества, что получило отражение в фундаментальных документах специализированных учреждений и программ ООН [ООН ... ; Зеленая экономика ..., 2019; Порфирьев, 2012; Ускова, 2009]. Экономической основой устойчивого развития и одним из наиболее перспективных инструментов его достижения и реализации является переход к зеленой экономике [Кожевников и др., 2019, с. 73].

Зеленая экономика выступает ответом на глобальные проблемы в экономической, социальной и экологической сферах. В настоящее время существует множество дефиниций понятия «зеленая экономика» [Кожевников и др., 2019; Порфирьев, 2012], однако наибольшую известность получило определение ЮНЕП (Программа ООН по окружающей среде - United Nations Environmental Programme), согласно которому зеленая экономика - это экономика, которая ведет к повышению благосостояния людей и социальной справедливости при значительном снижении экологических рисков и экологического дефицита [Кожевников и др., 2019, с. 73].

По мнению академика Б.Н. Порфирьева, в узком смысле «зеленая экономика - те виды и результаты хозяйственной деятельности, которые наряду с модернизацией и повышением эффективности производства способствуют улучшению качества жизни и среды обитания» [Порфирьев, 2012, с. 35].

Все существующие определения зеленой экономики содержат общие элементы, такие как экономия природных ресурсов, сокращение выбросов парниковых газов и других загрязняющих веществ, защита биоразнообразия, качество жизни, благосостояние человека и социальная интеграция [Порфирьев, 2012].

На международном уровне, в частности, государствами - членами Организации экономического сотрудничества и развития (далее - ОЭСР) в 2009 г. переход к зеленой экономике был провозглашен как официальная декларация дальнейшего развития, а с 2011 г. реализуется в качестве стратегии «зеленого» роста. Однако для России понятие 
«зеленая экономика» является относительно новым и в настоящее время оно не используется в официальных государственных документах. В то же время национальные цели развития, такие как социальное и экологическое благополучие, повышение энергоэффективности, охрана окружающей среды, рациональное природопользование и устойчивое развитие, во многом соотносятся с целями перехода к зеленой экономике [Кожевников и др., 2019, с. 77].

Полагая, что зеленая экономика является одним из инструментов достижения устойчивого развития, необходимо предложить способы измерения степени ее реализации.

Целью данной работы является сравнительный анализ наиболее известных методик оценки реализации концепции зеленой экономики на национальном и региональном уровнях, выявление их достоинств и недостатков.

\section{Результаты исследования}

В ходе анализа зарубежных и отечественных источников было установлено, что для этой цели, главным образом, используются различные интегральные (агрегированные) индексы. Последние должны обеспечить представление о явлении в целом, а набор отдельно взятых показателей - дать дополнительную информацию для лучшего понимания об изменениях во времени и/или различиях между исследуемыми объектами, обычно странами.

Среди них можно выделить 2 типа: 1) индексы, основанные на базе диагностических показателей, не имеющих общей единицы измерения и требующих проведения нормализации [International Experiences ... , 2006; Handbook on Constructing Composite Indicators ... , 2008; Nahman et al., 2016; UNEP ..., 2012]; 2) индексы, рассчитываемые на базе показателей с общей единицей измерения [Варавин и др., 2018; Эколого-экономический индекс ..., 2012; Veklych et al.].

При построении интегрального индекса выбор показателей должен быть обоснован следующими критериями: релевантность (соответствие рассматриваемому вопросу); точность и прозрачность; своев- ременность; доступность (легкость доступа к данным) и согласованность (логические связи и взаимная согласованность данных) [OECD Statistics, 2008].

Свои методики с соответствующими наборами показателей были предложены ЮНЕП [UNEP ..., 2012], Европейской Комиссией [Bucher], Всемирным банком, Глобальным институтом зеленого роста (GGGI) [Green Growth Potential Assessment, 2019] для стратегии и планирования зеленого роста, Платформой знаний о зеленом росте (Green Growth Knowledge Platform), Агентством США по охране окружающей среды (Environmental protection Agency, EPA), Глобальным партнерством между GGGI, ОЭСР, Всемирным банком и ЮНЕП, а также отдельными исследователями и частными компаниями (Dual Citizen) [Mcnally et al., 2018; Open Data Platform; UNEP ..., 2012].

Основные характеристики наиболее известных методик по оценке перехода к зеленой экономике представлены в таблице 1.

Сначала предлагаем рассмотреть методики расчета интегральных показателей, требующие нормализации составляющих компонентов.

Наиболее известным показателем такого рода является глобальный индекс зеленой экономики (Global Green Economy Index, GGEI), разработанный в 2010 г. и публикуемый раз в два года американской консалтинговой компанией Dual Citizen. Компонентные показатели объединены в 4 группы: лидерство и изменение климата; экономически эффективные секторы; рынки инвестиций; окружающая среда. Впервые GGEI был рассчитан в 2010 г., однако относительно России результаты расчетов были впервые опубликованы только в 2016 году. Интересной методической особенностью GGEI является расчет двух его типов: глобальный индекс зеленой экономики восприятия (GGEI Perception) и глобальный индекс зеленой экономики представления (GGEI Performance). Данные для расчета индекса восприятия собираются с помощью социологических опросов, а индекс представления - посредством статистики, балльной экспертной оценки (обычно ее осуществляет разработчик индикатора или самостоятельных расчетов). 


\section{Основные подходы к расчету интегральных индексов оценки перехода} к зеленой экономике

\begin{tabular}{|c|c|c|c|c|c|c|}
\hline Методика & $\begin{array}{c}\text { Количест- } \\
\text { во показа- } \\
\text { телей }\end{array}$ & $\begin{array}{c}\text { Методы } \\
\text { нормали- } \\
\text { зации } \\
\end{array}$ & Beca & $\begin{array}{l}\text { Конеч- } \\
\text { ный ре- } \\
\text { зультат }\end{array}$ & $\begin{array}{c}\text { Способ сбора и источники } \\
\text { информации }\end{array}$ & $\begin{array}{c}\text { Способы опреде- } \\
\text { ления интеграль- } \\
\text { ного показателя }\end{array}$ \\
\hline $\begin{array}{l}\text { Global } \\
\text { Green } \\
\text { Economy } \\
\text { Index } \\
\text { (Dual Citi- } \\
\text { zen) } \\
\text { [Mcnally } \\
\text { et al., } \\
2018 \text { ] }\end{array}$ & $\begin{array}{l}20 \text { инди- } \\
\text { каторов }\end{array}$ & $\begin{array}{l}\text { Стандар- } \\
\text { тизация } \\
\text { (z-score) }\end{array}$ & $\begin{array}{l}\text { Равновесные } \\
\text { группы ин- } \\
\text { дикаторов. } \\
\text { Внутри } \\
\text { групп (кро- } \\
\text { ме группы } \\
\text { «Лидерство } \\
\text { и изменение } \\
\text { климата») } \\
\text { индикаторы } \\
\text { также имеют } \\
\text { равные веса }\end{array}$ & $\begin{array}{l}\text { Балл в } \\
\text { диапазо- } \\
\text { не от } 0 \\
\text { до } 100\end{array}$ & $\begin{array}{l}\text { Источник: анализ } \\
\text { Google, экспертные } \\
\text { оценки Dual Citizen LLC } \\
\text { IEA, IRENA, CAN, } \\
\text { LEED, (USGBC), } \\
\text { WASTE ATLAS, Eco- } \\
\text { MENA, Cleantech Group, } \\
\text { Heslin, Rothenberg, Farley } \\
\text { \& Mesiti p.c., Environ- } \\
\text { mental Performance Index } \\
\text { (Йельский университет). } \\
\text { Способь сбора: анкет- } \\
\text { ный опрос, контент- } \\
\text { анализ документов }\end{array}$ & $\begin{array}{l}\text { Сумма средне- } \\
\text { взвешенных } \\
\text { арифметических } \\
\text { групповых пока- } \\
\text { зателей }\end{array}$ \\
\hline $\begin{array}{l}\text { Green } \\
\text { Economy } \\
\text { Index } \\
\text { [Nahman } \\
\text { et al., } \\
2016]\end{array}$ & $\begin{array}{l}26 \text { пока- } \\
\text { зателей } \\
\text { предло- } \\
\text { жены, } \\
\text { уточнены } \\
20\end{array}$ & $\begin{array}{l}\text { Нормали- } \\
\text { зация ми- } \\
\text { нимума- } \\
\text { максиму- } \\
\text { ма значе- } \\
\text { ний }\end{array}$ & Равные веса & $\begin{array}{l}\text { Балл в } \\
\text { диапазо- } \\
\text { не от } 0 \\
\text { до } 10\end{array}$ & $\begin{array}{l}\text { Источник: FAO, IEA, } \\
\text { IMF, FiBL, World Bank, } \\
\text { WRI, IUCN, (MDGs), } \\
\text { UNDP, ILO. } \\
\text { Cпособь сбора: контент- } \\
\text { анализ документов }\end{array}$ & $\begin{array}{l}\text { Расчет среднего } \\
\text { арифметическо- } \\
\text { го нормализо- } \\
\text { ванных показа- } \\
\text { телей }\end{array}$ \\
\hline $\begin{array}{l}\text { Green } \\
\text { Growth } \\
\text { Index } \\
{[\text { Acosta, }} \\
2019]\end{array}$ & $\begin{array}{l}30 \text { глав- } \\
\text { ных пока- } \\
\text { зателей и } \\
8 \text { вспомо- } \\
\text { гательных }\end{array}$ & $\begin{array}{l}\text { Нормали- } \\
\text { зация ми- } \\
\text { нимума- } \\
\text { максиму- } \\
\text { ма [0-1] }\end{array}$ & Уточняются & $0-100$ & $\begin{array}{l}\text { Источник: OECD, IEA, } \\
\text { ILO, FAO. } \\
\text { Способы сбора: контент- } \\
\text { анализ документов }\end{array}$ & $\begin{array}{l}\text { Линейное агреги- } \\
\text { рование нормали- } \\
\text { зованных показа- } \\
\text { телей, геометри- } \\
\text { ческое агрегиро- } \\
\text { вание групп пока- } \\
\text { зателей } \\
\end{array}$ \\
\hline $\begin{array}{l}\text { Индекс } \\
\text { скоррек- } \\
\text { тирован- } \\
\text { ных чис- } \\
\text { тых нако- } \\
\text { плений } \\
\text { [Зеленая } \\
\text { экономи- } \\
\text { ка ... , } \\
2012 \text { ] }\end{array}$ & $\begin{array}{l}8 \text { показа- } \\
\text { телей }\end{array}$ & $\begin{array}{l}\text { Нормали- } \\
\text { зация не } \\
\text { требуется. } \\
\text { Все вхо- } \\
\text { дящие в } \\
\text { расчет ве- } \\
\text { личины } \\
\text { беругся } \\
\text { денежных } \\
\text { единицах } \\
\text { измерения }\end{array}$ & $\begin{array}{l}\text { Все показа- } \\
\text { тели равно- } \\
\text { значны }\end{array}$ & $\begin{array}{l}\text { Измеря- } \\
\text { ется в \% } \\
\text { от ВРП }\end{array}$ & $\begin{array}{l}\text { Источник: Росстат. } \\
\text { Способы сбора: контент- } \\
\text { анализ документов }\end{array}$ & $\begin{array}{l}\text { Линейное агре- } \\
\text { гирование (сум- } \\
\text { ма показателей) }\end{array}$ \\
\hline $\begin{array}{l}\text { Экологи- } \\
\text { чески } \\
\text { адаптиро- } \\
\text { ванный } \\
\text { чистый } \\
\text { внутрен- } \\
\text { ний про- } \\
\text { дукт «Зе- } \\
\text { леный } \\
\text { ВВП» } \\
\text { [Internat io } \\
\text { nal Expe- } \\
\text { riences ... , } \\
\text { 2006] }\end{array}$ & $\begin{array}{l}4 \text { показа- } \\
\text { теля }\end{array}$ & $\begin{array}{l}\text { Нормали- } \\
\text { зация не } \\
\text { требует- } \\
\text { ся, все } \\
\text { показате- } \\
\text { ли ис- } \\
\text { пользу- } \\
\text { ются в } \\
\text { стоимо- } \\
\text { стной } \\
\text { форме }\end{array}$ & $\begin{array}{l}\text { Все показа- } \\
\text { тели равно- } \\
\text { значны }\end{array}$ & $\begin{array}{l}\text { В де- } \\
\text { нежных } \\
\text { едини- } \\
\text { цах ВВП }\end{array}$ & $\begin{array}{l}\text { Источник: UNEP, на- } \\
\text { циональные статистиче- } \\
\text { ские управления и служ- } \\
\text { бы. } \\
\text { Сnособы сбора: контент- } \\
\text { анализ документов }\end{array}$ & $\begin{array}{l}\text { Линейное агре- } \\
\text { гирование (сум- } \\
\text { ма показателей) }\end{array}$ \\
\hline
\end{tabular}


M.А. Лебедева. Сравнительный анализ методик оценки перехода к зеленой экономике

Окончание таблицьь 1

\begin{tabular}{|c|c|c|c|c|c|c|}
\hline Методика & $\begin{array}{l}\text { Количест- } \\
\text { во показа- } \\
\text { телей }\end{array}$ & $\begin{array}{c}\text { Методы } \\
\text { нормали- } \\
\text { зации }\end{array}$ & Beca & $\begin{array}{l}\text { Конеч- } \\
\text { ный ре- } \\
\text { зультат }\end{array}$ & $\begin{array}{c}\text { Способ сбора и источники } \\
\text { информации }\end{array}$ & $\begin{array}{c}\text { Способы опреде- } \\
\text { ления интеграль- } \\
\text { ного показателя }\end{array}$ \\
\hline $\begin{array}{l}\text { Экологи- } \\
\text { ческий } \\
\text { след } \\
\text { [Metodo- } \\
\text { logy ... } \\
2013 \text { ] }\end{array}$ & $\begin{array}{l}17 \text { пока- } \\
\text { зателей }\end{array}$ & $\begin{array}{l}\text { Коэффи- } \\
\text { циент эк- } \\
\text { вивалент- } \\
\text { ности пе- } \\
\text { реводя- } \\
\text { щий все } \\
\text { расчеты в } \\
\text { глобаль- } \\
\text { ные гек- } \\
\text { тары на } \\
\text { душу на- } \\
\text { селения }\end{array}$ & $\begin{array}{l}\text { Все показа- } \\
\text { тели равно- } \\
\text { значны }\end{array}$ & $\begin{array}{l}\text { В гло- } \\
\text { бальных } \\
\text { гектарах }\end{array}$ & $\begin{array}{l}\text { Источник: Global foot- } \\
\text { print network, FAO, IEA, } \\
\text { UNECE. } \\
\text { Способы сбора: контент- } \\
\text { анализ документов }\end{array}$ & $\begin{array}{l}\text { Сумма средне- } \\
\text { взвешенных } \\
\text { арифметичес- } \\
\text { ких групповых } \\
\text { индикаторов }\end{array}$ \\
\hline
\end{tabular}

Примечание. Составлено автором по: [Mcnally et al., 2018; Nahman et al., 2016; Acosta, 2019; Зеленая экономика ..., 2012; International Experiences ..., 2006; Metodology ..., 2013]. FAO - Food and Agriculture Organization; IEA - International Energy Agency; UNECE - United Nations Economic Commission for Europe; UNEP - The United Nations Environment Programme; IMF - International Monetary Fund, ILO - International Labour Organization; IRENA - International Renewable Energy Agency; CAN - Climate Action Network; LEED Leadership in Energy and Environmental Design; USGBC - The U.S. Green Building Council; FiBL Forschungsinstitut für biologischen Landbau (Research Institute of Organic Agriculture); WRI - World Resources Institute; IUCN - The International Union for Conservation of Nature; MDGs - Millennium Development Goals; UNDP - United Nations Development Programme.

Методика расчета предусматривает равные веса показателей в каждой их группе, за исключением группы «Лидерство и изменение климата». С целью устранения различий в единицах измерения нормализация составляющих показателей осуществляется путем стандартизации (z-score), который заключается в том, чтобы рассчитать среднее значение и значение стандартного отклонения для каждого показателя или набора данных, что, в свою очередь, позволяет рассчитать $z$-показатель и соответствующий процентиль (формула (1):

$$
I_{q c}^{t}=\frac{x_{q c}^{t}-x_{q c=\bar{c}}^{t}}{\sigma_{q c=\bar{c}}^{t}}
$$

где $I_{q c}^{t}$-нормализованное значение показателя $x_{q c}^{t}$, (z-показатель); $x_{q c}^{t}$-значение показателя $q$ за определенный год $t$ в стране $c ; x_{q c=\bar{c}}^{t}-$ среднее значение по рассматриваемым странам за 1 год; $\sigma_{q c=\bar{c}}^{t}-$ стандартное отклонение по рассматриваемым странам.

Затем эти процентильные значения можно агрегировать единообразно, получая балл по стране, который выражается в спектре 0100 [Tamanini et al., 2016].

По результатам расчета GGEI составляются соответствующие рейтинги стран мира. Так, в 2016 г. среди 80 стран мира по GGEI Perception Россия занимала 51 место, по GGEI Performance - 71 место [Tamanini et al., 2016]. В докладе за 2018 г. были охвачены 20 компонентных показателей за 2013-2017 гг. и 130 стран. В последнем отчете (2018 г.) был представлен рейтинг только по GGEI Performance, где Россия занимает 105-е место среди рассмотренных 130 стран [Mcnally et al., 2018]. Руководитель Dual Citizen Джереми Таманини указывает, что данный индекс может быть использован на субнациональном уровне [Tamanini et al., 2016], однако, на наш взгляд, данную методику достаточно сложно адаптировать под региональный уровень, во многом из-за группы показателей «Лидерство и изменение климата», так как отследить позитивное освещение в СМИ или информационно-пропагандистскую деятельность регионов государства по зеленым вопросам довольно затруднительно. Также возникает сложность использования данного индекса для отдельно рассматриваемой административной территории, так как он представляет собой рейтинговую оценку, которая направлена на сравнение объектов относительно друг друга.

Кроме того, полученные значения индекса не свидетельствуют о том, что в государ- 
стве концепция зеленой экономики реализована в полной мере, а только показывает, что в стране наблюдаются тенденции перехода к зеленой экономике, а с помощью рейтинга фиксируется, в каких странах они наиболее выражены. При этом не уточняется, какими пороговыми значениями обосновано значение верхней границы шкалы в 100 единиц.

Аналогичный подход был предпринят Антоном Нахманом, Брайаном Махумани и Виллемом де Ланже, в рамках которого был разработан индекс зеленой экономики (Green Economy Index, GEI) на основе 26 критериев, каждому из них соответствует один индикатор. Несмотря на то что 6 из 26 индикаторов требуют уточнения и многими странами не отслеживаются по причине их актуальности для зеленой экономики, исследователи решили, что их все равно необходимо учитывать при расчете индекса, чтобы данные по этим показателям включались в будущие оценки [Nahman et al., 2016].

Изначально в работе A. Nahman, B.K. Mahumani, W.J. de Lange планировалось рассчитать GEI для 193 стран, однако было решено не включать в выборку страны, где отсутствуют данные по 3 и более показателям (то есть более $10 \%$ от всего набора показателей), а по странам с отсутствующими одним или двумя показателями данные рассчитывались на основе средних значений аналогичных показателей стран одного и того же региона или стран с сопоставимым уровнем дохода по всей выборке [Nahman et al., 2016]. В результате данный индекс был рассчитан для 144 стран мира.

В данном случае нормализация производится по методу минимума-максимума значений (от 0 до 10, где 0 - антиидеальное решение, а 10 - идеальное решение), основанных на фактических или целевых показателях. Нормализация методом максимума-минимума для прямых (стимуляторов) и обратных (дестимулятров) показателей производится по формулам (2) и (3) [Godlewska et al., 2019].

$$
\begin{aligned}
& y_{j c t}=\frac{x_{j c t}-\min \left(x_{j c t}\right)}{\max \left(x_{j c t}\right)-\min \left(x_{j c t}\right)}, \\
& y_{j c t}=\frac{\min \left(x_{j c t}\right)-x_{j c t}}{\max \left(x_{j c t}\right)-\min \left(x_{j c t}\right)},
\end{aligned}
$$

где $y_{j c t}$ - нормализованное значение показателя $x_{j c t}$; $x_{j c t}$ - значение показателя $j$ по стране $c$ за год $t$.
Общий показатель индекса рассчитывался как простое среднее арифметическое нормализованных показателей.

Методика сводится к построению рейтинга стран в зависимости от значения GEI. В работе [Nahman et al., 2016, с.12-13] были опубликованы результаты расчетов относительно 15 лидеров и 15 аутсайдеров рейтинга по GEI, среди которых России не было. Но, несмотря на комплексность данной методики, к основным ее недостаткам можно отнести сложность поиска необходимых данных для расчета, а также то, что, как и в случае GGEI, данный индекс позволяет оценить не степень реализации концепции зеленой экономики, а только определенные тенденции «озеленения» экономики и сравнить по ним исследуемые страны.

Еще одной методикой определения интегрального показателя является индекс зеленого роста (Green Growth Index, GGI), предложенный ОЭСР в 2011 году. GGI рассчитывается на основе 23 главных показателей, некоторые из них требуют уточнения (это касается показателей биоресурсов, иностранных инвестиций и цен на воду). Нормализация показателей осуществляется на основе целевых показателей по методу минимумамаксимума в диапазоне от 0 до 1, где 0 анти-идеальное решение, а 1 - идеальное. В дальнейшем нормализованные показатели с учетом весов агрегируются в один показатель [Godlewska, 2019].

Данная методика была адаптирована для польских регионов Джоанной Годлевска и Эдитой Сидорчук-Пьетрашко [Godlewska et al., 2019]. Необходимость адаптации была вызвана недоступностью соответствующих национальному уровню статистических данных по регионам. Некоторые индикаторы, предложенные ОЭСР, были исключены, другие были переформулированы, исходя из доступности данных в статистических базах данных. Частично набор также был дополнен авторами. Всего было выделено 22 индикатора из 23 главных показателей, предложенных ОЭСР. Адаптированная методика была нацелена на расчет Регионального индекса зеленой экономики (RGEI) и сравнение всех польских регионов (воеводств) в период с 2004 по 2016 год. После нормализации показателей и определе- 
ния весов $\left(w_{j}\right)$ рассчитывались Евклидовы расстояния $\left(D_{i t}\right)$ значений индикаторов в каждом году от идеального $\left(D_{i t}^{+}\right)$и антиидеального $\left(D_{i t}^{-}\right)$значений [формулы (4) и (5)].

$$
\begin{aligned}
& D_{i t}^{+}=\sqrt{\sum_{J=1}^{m} w_{j} \times\left(y_{j i t}-y_{j}^{+}\right)^{2}}, \\
& D_{i t}^{-}=\sqrt{\sum_{J=1}^{m} w_{j} \times\left(y_{j i t}-y_{j}^{-}\right)^{2}} .
\end{aligned}
$$

На базисе значений Евклидовых расстояний по формуле (6) был рассчитан Региональный индекс зеленой экономики (RGEI):

$$
R G E I=\frac{D_{i t}^{-}}{D_{i t}^{+}+D_{i t}^{-}} .
$$

Такая методика так же, как и предыдущие, характеризует тенденции перехода к зеленой экономике на основе уже достигнутых когда-то целей по сравнению с другими территориями. По сути, данный показатель о качественном переходе к зеленой экономике свидетельствовать не может. Частные показатели, отбираемые для расчета, часто не имеют эталона, а явления, оцениваемые по ним, не всегда управляемы (например, таким показателем является «площадь территории под водой»), то есть ни население, ни органы власти даже при самом грамотном управлении не могут на такие показатели повлиять, а данный индекс будет учитывать это как недостаточность мер по переходу к зеленой экономике.

Среди всех интегральных показателей, составные элементы которых требуют нормализации, следует выделить такой индекс, как экологический след (Ecological footprint) [Metodology ..., 2013]. Экологический след человека рассчитывается путем сложения всех потребностей людей, которые конкурируют за биологически продуктивное пространство, такое как пахотные земли для выращивания картофеля или хлопка, леса для производства древесины или для поглощения выбросов углекислого газа. В отличие от уже рассмотренных индексов экологический след измеряется в глобальных гектарах на душу населения. Глобальные гектары по отношению к экологическому следу представляют собой количество биологического материала, полезного для человека, которое производится на данной территории. Поскольку мировая биопро- дуктивность меняется из года в год, значение глобального гектара - аналогично ей. Данный индекс показывает, как антропогенная нагрузка снижает биологическую емкость природы и позволяет вычислить биозащитный резерв или дефицит. В то же время только по этому показателю (без учета биоемкости территории) нельзя оценить степень «озеленения» экономики, так как при расчете социально-экономическим вопросам внимание не уделяется.

Экологический след является одним из наиболее сложных для вычисления показателей. К тому же он плохо поддается адаптации на региональном уровне. Как правило, расчет экологического следа с использованием полных исходных данных возможен только в глобальном или национальном масштабе. Анализ экологического следа требует больших объемов данных, а статистика производства и торговли по всем отраслям и видам экономической деятельности, охватываемым методологией экологического следа, редко собирается на субнациональном уровне [Metodology ..., 2013]. На региональном уровне экологический след рассчитан только в отношении Калифорнии по причине максимально полной обеспеченности необходимыми данными.

По данным Глобальной сети, для измерения экологического следа используются два подхода: «снизу вверх» и «сверху вниз» [Metodology ..., 2013, с. 5].

Метод «снизу вверх» подсчитывает экологический след всех отдельных продуктов, потребляемых субнациональным населением, и суммирует их вместе [Metodology ..., 2013, с. 5].

Метод «сверху вниз» начинается с результатов экологического следа, рассчитанных на национальном уровне с использованием национальных счетов экологического следа. Затем получают субнациональные следы, корректируя различия в потреблении между национальным и субнациональным населением. Точнее, он растягивает (или сокращает) каждый компонент национального следа для относительных различий между средним национальным потреблением в этом компоненте и соответствующим потреблением субнационального населения [Metodology ..., 2013, с. 5]. 
Для нормализации используются коэффициенты эквивалентности (equivalence factor, $\mathrm{EQF})$, которые позволяют выразить результаты анализа экологического следа в глобальных гектарах на душу населения, обеспечивая сопоставимость между экологическими следами стран, а также значениями биоемкости. Коэффициенты эквивалентности рассчитываются как отношение максимальной потенциальной экологической продуктивности среднемировых земель определенного типа (например, пахотных) и средней продуктивности всех биологически продуктивных земель на Земле [Metodology ..., 2013, с. 8].

Таким образом, можно сделать вывод о том, что интегральные показатели, для расчета которых требуется нормализация составных элементов в силу различных единиц измерения, отлично подходят для оценки тенденций перехода к зеленой экономике, но о степени ее реализации по ним судить нельзя. Кроме того, входящие в набор для расчета частные индикаторы часто обусловлены исключительно природными условиями конкретной территории, и, соответственно, при невозможности управления они будут свидетельствовать о недостаточности усилий по переходу к зеленой экономике.

Также следует отметить, что из требований к показателям, предъявляемых ОЭСР, индикаторы, составляющие интегральный индекс, не полностью соответствуют критериям легкости и доступности информации, прозрачности и согласованности. Так, например, некоторые составляющие элементы GGEI оценивались экспертами Dual Citizen по балльной шкале, которая не публикуется, другие индикаторы могли быть определены в результате социологического опроса или упоминаниями в СМИ, точное количество которых определить практически невозможно.

При использовании методик расчета интегрального индекса, составляющие которого не требуют нормализации по причине общих единиц измерения, необходимо отметить, что при адаптации к региональному уровню составные показатели не могут быть изменены вне зависимости от доступности данных.

К интегральным индексам, в которых составные индикаторы не требуют нормали- зации, относятся «зеленый ВВП» и индекс скорректированных чистых накоплений, на основе которого был разработан эколого-экономический индекс регионов РФ.

По мнению авторов [Зеленая экономика ..., 2012, с. 20], индекс скорректированных чистых накоплений (adjusted net savings) является одним из наиболее проработанных в теоретическом плане, имеющим хорошую статистическую базу и возможность расчета на страновом и региональном уровнях. Некоторые авторы считают его непосредственно индексом «зеленой экономики», в которой социальные аспекты сбалансированы с экологическими [Тяглов и др., 2017, с. 75].

Индекс скорректированных чистых накоплений характеризует скорость накопления национальных сбережений после надлежащего учета истощения природных ресурсов и ущерба от загрязнения окружающей среды [Зеленая экономика ..., 2012].

Скорректированные чистые накопления $(G S)$ рассчитываются по формуле (7):

$$
G S=G N S-D h+C S E-D p-C D-P D
$$

где $G N S$ - валовые внутренние сбережения; $D h$ обесценение основного капитала; $D p$ - истощение природных ресурсов; $C S E$ - текущие расходы на образование; $C D$ - ущерб от выбросов $\mathrm{CO}_{2} ; P D$ ущерб от выбросов твердых взвешенных частиц диаметром меньше 10 микрон.

По сути, $G S$ представляет собой валовые внутренние накопления, суммированные с текущими расходами на образование за вычетом экологического ущерба, изъятия исчерпаемых природных ресурсов. Все входящие в расчет величины берутся в процентах от валового национального дохода [Зеленая экономика ..., 2012].

Данная методика была адаптирована для регионального уровня, а адаптированный индекс получил название «эколого-экономический индекс». Целью разработки этого индекса стало создание такого показателя, который отражает экологическую ситуацию в регионах РФ и эколого-экономическую устойчивость их развития [Зеленая экономика ..., 2012]. Основой для данного показателя стал индекс скорректированных чистых накоплений (далее - ИСЧН), рассчитываемый как отно- 
шение скорректированных чистых накоплений к ВРП, умноженное на $100 \%$.

Скорректированные чистые накопления для регионов рассчитываются по формуле (8):

$$
\begin{aligned}
\text { СЧН } & =\text { ВН }- \text { ИД }- \text { ИПР }- \text { УЗОС }+ \\
& + \text { РЧК }+30 \mathrm{O}+\text { ООПТ, }
\end{aligned}
$$

где ВН - валовые накопления основного капитала (оценка производится на основе инвестиций в основной капитал); ИД - инвестиции в основной капитал по виду деятельности «Добыча полезных ископаемых»; ИПР - истощение природных ресурсов; УЗОС - ущерб от загрязнения окружающей среды; РЧК - расходы на развитие человеческого капитала; 3ОС - затраты на охрану окружающей среды; ООПТ - оценка особо охраняемых природных ресурсов.

ИПР вычисляется как сумма истощения минерально-сырьевых ресурсов и лесных древесных ресурсов.

УЗОС как сумма ущерба от выбросов углекислого газа и загрязняющих веществ в атмосферный воздух (рассчитывается как произведение объема выбросов и среднего ущерба от одной тонны выброшенных загрязняющих веществ). Однако относительно этой составляющей возникает вопрос: почему учитывается ущерб только в отношении воздушной среды и не учитывается, например, ущерб от загрязнения воды и почвы.

РЧК рассчитываются как сумма расходов бюджетов различных уровней на образование, здравоохранение, физическую культуру.

ЗОС оцениваются по статистическому показателю «Расходы на охрану окружающей среды по видам природоохранной деятельности».

Оценка ООПТ производится по формуле (9):

$$
\text { ООПТ }=\frac{\text { ВРП } \cdot \text { ООПТ } \%}{100-\text { ООПТ } \%},
$$

где ООПТ \% - доля площади ООПТ в общей площади территорий, \%.

Данная методика также была апробирована авторами [Зеленая экономика ... , 2012] относительно всех регионов России в 2012 г., а в 2018 г. в отношении регионов Казахстана
Е.В. Варавиным и М.В. Козловой [Варавин и др., 2018].

Основным достоинством данной методики является то, что для расчета экологоэкономического индекса для регионов используются только данные официальной статистики. Во-первых, все используемые данные изначально стандартизированы, это позволяет исключить этап нормализации. Во-вторых, использование статистических данных минимизирует фактор субъективности. В-третьих, данные официальной статистики находятся в открытом доступе, что делает индекс абсолютно прозрачным [Зеленая экономика ... , 2012]. Своим алгоритмом расчета ИСЧН несколько схож с показателем биозащитного резерва / дефицита, определяемого при расчете экологического следа, однако ИСЧН значительно проще для вычисления.

К главным недостаткам можно отнести весьма низкую оперативность публикации статистических данных, а также и то, что в настоящее время не установлено эталонного значения ИСЧН, соответственно, оценить насколько данный показатель региона близок к идеалу невозможно, а показатель может быть использован для сравнения тенденций в сторону перехода к зеленой экономике в регионах [Зеленая экономика ..., 2012].

Кроме того, при анализе полученных результатов авторы данной методики указали, что в 2012 г. Ханты-Мансийский автономный округ Югра (далее - ХМАО) занимал 82-е место из 83 по значению эколого-экономического индекса с показателем ИСЧН - 45,7 \% к ВРП. Отрицательное значение обусловлено внушительными объемами добычи углеводородного сырья (в структуре ВРП региона на долю добычи полезных ископаемых приходится более $60 \%$ ). Причем доходы от добычи углеводородов остаются одним из основных источников доходной части бюджета страны, которые в дальнейшем распределяются среди дотационных регионов. Таким образом, сокращение природного капитала ХМАО обеспечивает инвестиции в других регионах, а следовательно их развитие. Среди позитивных факторов региона необходимо назвать относительно невысокий ущерб от вредных выбросов и высокий абсолютный объем расходов на охрану окружающей среды и на развитие чело- 
веческого капитала [Зеленая экономика ..., 2012, c. 136].

Самое высокое значение ИСЧН было в Республике Алтай (215,4% к ВРП). При этом обусловлено оно низким значением ВРП, а абсолютное значение скорректированных чистых накоплений составило всего 42,9 млрд рублей. Истощение природных ресурсов незначительно (менее $2 \%$ ВРП), но только не по причине применения инновационных ресурсосберегающих технологий, а из-за их изначального малого запаса в регионе и поэтому низкого объема добычи [Зеленая экономика ..., 2012, с. 133]. Соответственно, скорректированные чистые накопления в большей степени зависят не от грамотного управления и соответствующих решений, а от исходных природных условий, вследствие чего нарушается один из принципов зеленой экономики, согласно которому модель зеленой экономики может адаптироваться к различным культурным, социальным и экологическим особенностям любой страны. В связи с этим, на наш взгляд, используемые показатели должны быть управляемыми, а не обусловленными исключительно природными условиями.

Еще одним интегральным индексом, не требующим нормализации его составляющих, является «зеленый ВВП». По алгоритму расчета он практически повторяет ИСЧН, за исключением социальной составляющей, которая в случае «зеленого ВВП» не учитывается.

К региональному уровню данная методика не была адаптирована, и, наверное, при возможности более простого расчета ИСЧН адаптированный вариант, скорее всего, будет не востребован.

«Зеленый ВВП» рассчитывается по формуле (10):

$$
\text { "Green GDP" }=G D P-C N R-E D-E P E \text {, }
$$

где "Green GDP" - «зеленый ВBП»; GDP - ВBП; $C N R$ - Потребление природных ресурсов или истощение запаса природных ресурсов; $E D$ - Деградация окружающей среды или вред окружающей среде, обусловленный хозяйственной деятельностью; $E P E$ - природоохранные расходы [Veklych et al.].

К достоинствам «зеленого ВВП» можно отнести те же характеристики, что и у ИСЧН, однако возникает вопрос в отношении доступности данных. Так, если при расчете ИСЧН в составной индикатор истощения природных ресурсов входят соответствующие показатели относительно минерального и древесного сырья, то пояснений относительно расчета истощения природных ресурсов для «зеленого ВВП» нет, соответственно, возникает вопрос: необходимо рассчитать потребление всех видов ресурсов или можно ограничиться также только древесными и минеральными. К недостаткам «зеленого ВВП» также относится невысокая оперативность публикации статистических данных.

В целом результаты применения рассмотренных методик сильно разнятся. Так как они предполагают не только расчет и построение рейтинга, полученные оценки развития зеленой экономики предлагаем рассмотреть на примере первых пяти стран в рейтинге каждого интегрального показателя на 2016 г. (см. табл. 2). В таблице 2 не представлены результаты расчета по таким индексам GEI и «Зеленый ВВП» по причине того, что их применение не осуществляется на регулярной основе и результатов их расчета на международном и глобальном уровнях нет.

При сравнении оценок можно увидеть следующее: при использовании методик, где большое внимание уделяется социально-экономическому развитию (GGEI), среди лидеров, как правило, находятся экономически развитые страны, которые на международном уровне заявляют о своей приверженности к устойчивому развитию и зеленой экономике. Как отмечалось ранее, разница в GGEI Perception и GGEI Performance обусловлена отличающимися исходными данных, собранными разными методами [Tamanini et al., 2016].

При расчете GGI в 2016 г. в пятерку стран-лидеров вошли как экономически развитые европейские страны, так и три африканских развивающихся государства. Причиной этого стала превалирующая роль экологической составляющей в данной методике, особенно в отношении антропогенной нагрузки и использования невозобновляемых ресурсов.

В рейтингах по ИСЧН и Экологическому следу топ-5 стран лидеров составляют исключительно развивающиеся страны. Так как одними из ключевых составляющих дан- 
M.А. Лебедева. Сравнительный анализ методик оценки перехода к зеленой экономике

Таблища 2

Топ-5 стран в рейтингах интегральных показателей зеленой экономики в 2016 г.

\begin{tabular}{|c|c|c|c|c|c|}
\hline \multirow{2}{*}{$\begin{array}{l}\text { Место страны } \\
\text { в рейтинге }\end{array}$} & \multicolumn{2}{|c|}{ GGEI } & \multirow{2}{*}{ GGI } & \multirow{2}{*}{ ИСЧН } & \multirow{2}{*}{ Экологический след } \\
\hline & Perception & Performance & & & \\
\hline 1 & $\begin{array}{c}\text { Германия } \\
(97,74)\end{array}$ & $\begin{array}{c}\text { Швеция } \\
(77,61)\end{array}$ & $\begin{array}{c}\text { Республика } \\
\text { Конго } \\
(35,72)\end{array}$ & $\begin{array}{c}\text { Бруней- } \\
\text { Даруссалам } \\
(44,7)\end{array}$ & Эритрея $(0,5)$ \\
\hline 2 & $\begin{array}{c}\text { США } \\
(94,74)\end{array}$ & $\begin{array}{l}\text { Норвегия } \\
(69,11)\end{array}$ & $\begin{array}{c}\text { Эфиопия } \\
(15,45)\end{array}$ & $\begin{array}{r}\text { Макао } \\
(43,8)\end{array}$ & Таджикистан $(0,9)$ \\
\hline 3 & $\begin{array}{l}\text { Дания } \\
(93,84) \\
\end{array}$ & $\begin{array}{c}\text { Финляндия } \\
(67,83)\end{array}$ & $\begin{array}{c}\text { Швейцария } \\
(14,24)\end{array}$ & $\begin{array}{c}\text { Сингапур } \\
(31,9)\end{array}$ & Республика Конго $(1,1)$ \\
\hline 4 & $\begin{array}{l}\text { Швеция } \\
(93,65)\end{array}$ & $\begin{array}{c}\text { Швейцария } \\
(67,63)\end{array}$ & $\begin{array}{c}\text { Швеция } \\
(13,20) \\
\end{array}$ & $\begin{array}{c}\text { Непал } \\
(29,5)\end{array}$ & $\begin{array}{c}\text { Центральная Африканская } \\
\text { Республика }(1,20)\end{array}$ \\
\hline 5 & $\begin{array}{c}\text { Норвегия } \\
(88,95)\end{array}$ & $\begin{array}{c}\text { Германия } \\
(66,01)\end{array}$ & $\begin{array}{c}\text { Камерун } \\
(13,02)\end{array}$ & $\begin{array}{c}\text { Алжир } \\
(29,3)\end{array}$ & Лесото $(1,4)$ \\
\hline
\end{tabular}

Примечание. Составлено автором по: [Tamanini et al., 2016; Green Growth ... , 2019; Adjusted Savings ... , 2020; Open Data Platform, 2020].

ных индексов являются выброс парниковых газов и твердых частиц, большие значения которых свойственны, как правило, государствам с сильно развитой промышленностью, становится ясным именно такое распределение. При этом в то же время социально-экономическим аспектам не уделено должного внимания [Open Data Platform, 2020].

Как было отмечено ранее, только по экологическому следу (без учета биоемкости территории) нельзя оценить степень «озеленения» экономики. Так, у многих стран с минимальным экологическим следом наблюдается или небольшой или даже отрицательный экологический резерв (Эритрея, Таджикистан, Лесото). В связи с этим можно сделать вывод о том, что экологический след может полноценно применяться только вкупе с биоемкостью территории, главным образом для определения эффекта декаплинга и ассимиляционного потенциала [Open Data Platform, 2020].

\section{Выводы}

Сравнительный анализ показал, что существующие методики оценки перехода к зеленой экономике, главным образом, оценивают изменение тенденций в «озеленении» хозяйственной деятельности, а полноту реализации концепции характеризуют мало. Большинство из них являются рейтинговыми оценками и их применение направлено на сравнение каких-либо административных территорий. Также стоит подчеркнуть, что помимо критериев, предъявляемых ОЭСР к отбору частных показателей, стоит добавить и такие как управляемость и наличие эталонного значения, так как оценить уровень перехода к зеленой экономике без сравнения с другими территориями довольно затруднительно.

Интегральные показатели, у которых составные элементы требуют нормализации, с одной стороны, могут быть изменены в соответствии с наличием необходимых данных о регионе, с другой - это позволяет сравнивать регионы только с идентичными наборами показателей. Регионы, у которых были использованы пусть и близкие показатели по содержанию, сравнивать, на наш взгляд, не совсем корректно, так как каждый из индикаторов может быть истолкован по-разному (например, быть как стимулятором, так и дестимулятором для разных территорий), что повлияет на результаты расчета. Соответственно, в таких условиях, даже в рамках одной методики, нормализация этих показателей будет происходить с использованием разных формул. Относительно интегральных индексов (ИСЧН и «Зеленый ВВП»), для расчета которых не требуется нормализация, такой проблемы не возникает, в то же время низкая оперативность публикации статистических данных в определенной степени провоцирует также задержку расчета.

С учетом выявленных достоинств и недостатков наиболее известных методик в дальнейшем планируется разработать систему показателей и интегральный индекс, позволяющие оценить не только тенденции, но и 
насколько конкретные территории близки или далеки от полноценной реализации концепции зеленой экономики.

\section{ПРИМЕЧАНИЕ}

${ }^{1}$ Статья подготовлена в соответствии с государственным заданием для ФГБУН «Вологодский научный центр РАН» по теме НИР № 0168-2019-0004 «Совершенствование механизмов развития и эффективного использования потенциала социальноэкономических систем».

The paper was prepared in accordance with the state objective for Vologda Research Center of the Russian Academy of Sciences on research topic no. 0168-2019-0004 "Improvement of development mechanisms and efficient usage of social and economic systems' potential".

\section{СПИСОК ЛИТЕРАТУРЫ}

Варавин, Е. В. Оценка развития зеленой экономики в регионе (на примере Республики Казахстан) / Е. В. Варавин, М. В. Козлова // Экономика региона. - 2018. - Т. 14, № 4. - С. 1282-1297.

Зеленая экономика и цели устойчивого развития: коллектив. моногр. / под ред. С. Н. Бобылева, П. А. Кирюшина, О. В. Кудрявцевой. - М. : Экономический факультет МГУ им. М.В. Ломоносова, 2019. - 284 с.

Кожевников, С. А. Проблемы перехода к зеленой экономике в регионе (на материалах Европейского Севера России) / С. А. Кожевников, М. А. Лебедева // Проблемы развития территории. - 2019. - Т. 102, № 4. - С. 72-88.

Лабыкин, А. Бизнес уже платит за будущее планеты / А. Лабыкин, 3. Мамедьяров // Эксперт. 2020. - T. 1149, № 5. - С. 58-62.

ООН. Повестка дня на XXI век. 1992. - Электрон. текстовые дан. - Режим доступа: https:/www. un.org/ru/documents/decl conv/conventions/ agenda21.shtml (дата обращения: 18.02.2020). Загл. с экрана.

Порфирьев, Б. Н. «Зеленая экономика»: реалии, перспективы и пределы роста / Б. Н. Порфирьев // Экономика. Налоги. Право. - 2012. № 5. - С. 34-42.

Порфирьев, Б. Н. «Зеленый» фактор экономического роста в мире и в России / Б. Н. Порфирьев // Проблемы прогнозирования. - 2020. T. 170, № 5. - C. 3-12.

Проблемы экономического роста территории / Т. В. Ускова [и др.]. - Вологда : ИСЭРТ РАН, 2013. $-170 \mathrm{c}$.
Тяглов, С. Г. Современные аспекты развития «зеленой экономики» в Российской Федерации : монография / С. Г. Тяглов, Н. Н. Киселева, В. А. Тимченко. - Ростов н/Д : Содействие XXI век, 2017. - $104 \mathrm{c}$.

Ускова, Т. В. Управление устойчивым развитием региона : монография / Т. В. Ускова. - Вологда: ИСЭРТ РАН, 2009. - 255 с.

Эколого-экономический индекс регионов РФ / С. Н. Бобылев [и др.]. - M. : WWF России : РИА Новости, 2012. - 152 с.

Acosta, L. A. Green Growth Index. Concept, Mehods and Application / L. A. Acosta. - Seoul : [s. n.], 2019. - $101 \mathrm{p}$.

Adjusted Savings: Net National Savings (\% of GNI).Electronic text data. - Mode of access: https:// databank.worldbank.org/reports.aspx?source= $2 \&$ series $=$ NY.ADJ. NNTY.CD\&country (accessed 31 April 2020). - Title from screen.

Bucher, A. iGrowGreen an Indicator-Based Assessment Framework to Identify EU Member States' Challenges Towards Greener Growth Green. 2011 / A. Bucher.-Electronic text data.-Mode of access: https:/ec.europa.eu/environment/archives/ greenweek2011/sites/default/files/1-8_Bucher. pdf. - Title from screen.

Godlewska, J. Taxonomic Assessment of Transition to the Green Economy in Polish Regions / J. Godlewska, E. Sidorczuk-Pietraszko // Sustainability. - 2019. - Vol. 11, no. 18. Electronic text data. - Mode of access: https:// www.mdpi.com/2071-1050/11/18/5098. - Title from screen.

Green Growth Potential Assessment-Methodology Report. - Seoul: Global Green Growth Institute, 2019. - 162 p.

Handbook on Constructing Composite Indicators: Methodology and UserGuide. OECD. - Paris : [s. n.], 2008. - 162 p.

International Experiences with "Green GDP" / K. H. Alfsen [et al.]. - Oslo : Statistics Norway, 2006. - 43 p.

Mcnally P., Milla V. Global Green Economy Index (GGEI) 2018 Data / P. Mcnally, V. Milla. - 2018. Electronic text data. - Mode of access: https:// dualcitizeninc.com/global-green-economyindex. - Title from screen.

Methodology for Calculating the Ecological Footprint of California Review / D. Moore [et al.]. - Oakland : Global Footprint New York, 2013. - 47 p.

Nahman, A. Beyond GDP: Towards a Green Economy Index / A. Nahman, B. K. Mahumani, W. J. de Lange// Dev. South. Afr. - 2016. - Vol. 33, no. 2. P. 215-233.

OECD Statistics. - Electronic text data. - Mode of access: https://stats.oecd.org (accessed 31 May 2020). - Title from screen. 
Open Data Platform. - Electronic text data. - Mode of access: http://data.footprintnetwork.org/\# (accessed 31 May 2020). - Title from screen.

Tamanini, J. The Global Green Economy Index GGEI 2016/ J. Tamanini, J. Valenciano. - 2016. - № 5. Electronic text data. - Mode of access: https:// dualcitizeninc.com/GGEI-2016.pdf. - Title from screen.

UNEP. Green Economy. Briefing Paper Metrics and Indicator. Geneva, 2012. - Electronic text data. Mode of access: https://wedocs.unep.org/ bitstream/handle/20.500.11822/8659/-\%20Green $\% 20$ economy_\%20what $\% 20 \mathrm{do} \% 20 \mathrm{we} \% 20$ mean $\% 20$ by\%20green\%20economy_\%20-2012Main $\%$ 20briefing\%202012--Final.pdf. - Title from screen.

Veklych O., Shlapak M. Green GDP as an Indicator of Environmental Cost of Economic Growth in Ukraine / O. Veklych, M. Shlapak. - Electronic text data. - Mode of access: https://archive.org/ strea m/ Green Gd p A s An Indicator OfEnvironmentalCostOfEconomicGrowth InUkraine/Veklych.Shlapak. GreenGdpAs AnIndicatorOfEnvironmentalCostOfEconomic GrowthOfUkraine_djvu.txt. (accessed 31 May 2020). - Title from screen.

\section{REFERENCES}

Varavin E.V., Kozlova M.V. Otsenka razvitiya zelenoy ekonomiki $\mathrm{v}$ regione (na primere Respubliki Kazahstan) [Assessment of the Development of the Green Economy in the Region (in the Republic of Kazakhstan)]. Ekonomika regiona [Economy of Region], 2018, vol. 14, no. 4, pp. 1282-1297.

Bobylev S.N., Kirjushin P.A., Kudrjavceva O.V., eds. Zelenaya ekonomika $i$ tseli ustoychivogo razvitiya: kollektiv. monogr. [Green Economy and Sustainable Development Goals. Collective Monograph]. Moscow, Ekonomicheskiy fakultet MGU im. M.V. Lomonosova, 2019.284 p.

Kozhevnikov S.A., Lebedeva M.A. Problemy perekhoda $\mathrm{k}$ zelenoy ekonomike $\mathrm{v}$ regione (na materialakh Evropeyskogo Severa Rossii) [Problems of Transition to Green Economy in the Region (Based on Materials of the European North of Russia)]. Problemy razvitiya territorii [Problems of Territorys Development], 2019, vol. 102 , no. 4 , pp. $72-88$.

Labykin A. Mamedjarov Z. Biznes uzhe platit za budushchee planety [Business Already Pays for the Future of the Planet]. Ekspert [Expert], 2020, vol. 1149 , no. 5, pp. 58-62.

OON. Povestka dnya na XXI vek. 1992 [UN. Agenda 21. 1992]. URL: https://www.un.org/ru/documents/ decl_conv/conventions/agenda 21 .shtml (accessed 18 February 2020).

Porfirev B.N. «Zelenaya ekonomika»: realii, perspektivy i predely rosta [“Green Economy”: Realities, Prospects and Limits of Growth]. Ekonomika. Nalogi. Pravo [Economy. Taxes. Right], 2012, no. 5, pp. 34-42.

Porfirev B.N. «Zelenyy» faktor ekonomicheskogo rosta v mire i v Rossii [The "Green" Factor of Economic Growth in the World and in Russia]. Problemy prognozirovaniya [The Problems of Forecasting], 2020, vol. 170, no. 5, pp. 3-12.

Uskova T.V. et al. Problemy ekonomicheskogo rosta territorii [Problems of Economic Growth of the Territory]. Vologda, ISERT RAN Publ., 2013. $170 \mathrm{p}$.

Tjaglov S.G., Kiseleva N.N., Timchenko V.A. Sovremennye aspekty razvitiya «zelenoy ekonomiki» $v$ Rossiyskoy Federatsii: monografiya [Modern Aspects of the Development of the Green Economy in the Russian Federation. Monograph]. Rostov-onDon, Sodeystvie - XXI vek Publ., 2017. 104 p.

Uskova T.V. Upravlenie ustoychivym razvitiem regiona: monografiya [Regional Sustainability Management. Monograph]. Vologda, ISERT RAN Publ., 2009. 255 p.

Bobylev S.N. et al. Ekologo-ekonomicheskiy indeks regionov $R F$ [Ecological and Economic Index of the Regions of the Russian Federation]. Moscow, WWF Rossii Publ., RIA Novosti Publ., 2012. 152 p.

Acosta L.A. Green Growth Index. Concept, Mehods and Application. Seoul, [s. n.], 2019. 101 p.

Adjusted Savings: Net National Savings (\% of GNI). URL:https://databank.worldbank.org/reports. aspx ? source $=2 \&$ series $=$ NY.ADJ.NNTY.CD\& country (accessed 31 April 2020).

Bucher A. iGrowGreen an Indicator-Based Assessment Framework to Identify EU Member States Challenges Towards Greener Growth Green 2011. URL: https://ec.europa.eu/ environment/archives/greenweek2011/sites/ default/files/1-8_Bucher.pdf.

Godlewska J., Sidorczuk-Pietraszko E. Taxonomic Assessment of Transition to the Green Economy in Polish Regions. Sustainability, 2019, vol. 11, no. 18. URL: https://www.mdpi.com/2071-1050/ 11/18/5098.

Green Growth Potential Assessment-Methodology Report. Seoul, Global Green Growth Institute, 2019. $162 \mathrm{p}$.

Handbook on Constructing Composite Indicators: Methodology and UserGuide. OECD. Paris, [s. n.], 2008. 162 p. 


\section{УПРАВЛЕНИЕ ЭКОНОМИЧЕСКИМ РАЗВИТИЕМ}

Alfsen K.H. et al. International Experiences with “Green GDP”. Oslo, Statistics Norway, 2006. 43 p.

Mcnally P., Milla V. Global Green Economy Index (GGEI) 2018 Data. URL: https://dualcitizeninc. com/global-green-economy-index.

Moore D., Larson J., Iha K., Gracey K., Wackernagel M., Lenning R., Mattoon S., Connaway J. Methodology for Calculating the Ecological Footprint of California Review. Oakland, Global Footprint New York, 2013.47 p.

Nahman A., Mahumani B.K., de Lange W.J. Beyond GDP: Towards a Green Economy Index. Dev. South. Afr., 2016, vol. 33, no. 2, pp. 215-233.

OECD Statistics. URL: https://stats.oecd.org/ (accessed 31 May 2020).

Open Data Platform. URL: http://data. footprintnetwork.org/\# (accessed 31 May 2020).
Tamanini J., Valenciano J. The Global Green Economy Index GGEI 2016, 2016, no. 5. URL: https:// dualcitizeninc.com/GGEI-2016.pdf.

UNEP. Green Economy. Briefing Paper Metrics and Indicator. Geneva, 2012. URL: https://wedocs. unep.org/bitstream/handle/20.500.11822/8659/ $\% 20$ Green $\% 20$ economy_\%20what $\% 20$ do $\%$ 20we\%20mean $\% 20$ by $\% 20$ green $\% 20$ economy_\% 20-2012Main\%20briefing\%202012-Final.pdf.

Veklych O., Shlapak M. Green GDP as an Indicator of Environmental Cost of Economic Growth in Ukraine. URL: https://archive.org/stream/ GreenGdpAsAnIndicatorOfEnvironmental CostOfEconomicGrowthInUkraine/Veklych. Shlapak. Green GdpAs An IndicatorOf EnvironmentalCostOfEconomicGrowthOf Ukraine_djvu.txt (accessed 31 May 2020).

\section{Information About the Author}

Marina A. Lebedeva, Research Engineer, Department for Issues of Socio-Economic Development and Management in Territorial Systems, Vologda Research Center of the Russian Academy of Sciences, Gorkogo St, 56a, 160014 Vologda, Russian Federation, lebedevamarina1@mail.ru, https://orcid.org/0000-0002-7310-6143

\section{Информация об авторе}

Марина Анатольевна Лебедева, инженер-исследователь отдела проблем социальноэкономического развития и управления в территориальных системах, Вологодский научный центр PAН, ул. Горького, 56a, 160014 г. Вологда, Российская Федерация, lebedevamarina1@mail.ru, https://orcid.org/0000-0002-7310-6143 